\title{
Step into Drama and Teach English affordably
}

\author{
A Case Study from Greece.
}

\section{Konstantina Kalogirou}

\begin{abstract}
This paper demonstrates how drama was used as a teaching tool in an English as a Foreign Language class in a Greek primary school. This paper presents, in particular, the origins, values and principles of Drama in Education (DiE) while exploring why drama is considered a suitable and efficient learning medium in a country that currently struggles with an economic crisis, which undoubtedly affects the education sector. While Greek schools suffer from staff shortages and limited equipment, there is an urgency for innovative, motivating, and affordable teaching methodologies that activate learners, bridge the gaps left by current teaching approaches, and encourage learners to safely immerse themselves in the target language. Finally, this paper sketches the motivating, engaging, and efficient contribution of DiE to language learning processes and claims it to be an adaptable and affordable teaching medium for any language teacher. ${ }^{1}$
\end{abstract}

Tell me and I forget, teach me and I may remember, involve me and I learn.

Benjamin Franklin

\section{Introduction}

This paper has a threefold scope: firstly, to introduce Drama in Education (DiE) as a term; secondly, to outline its principles; and thirdly, to discuss its approach to teaching English as a foreign language in the Greek educational system. Readers will be introduced to the Greek educational system, its grading, and the current teaching methods of English as a Foreign Language, in order to explain why DiE is considered a different, innovative and motivating teaching tool. Secondly, this paper will point out the reasons for DiE being an auspicious foreign language approach in the context of a financial crisis where funds for staff, resources and equipment are limited. Finally, this paper will outline the

\footnotetext{
1 This paper has been presented by the writer in the 8th World Congress of IDEA - the International Drama/Theatre and Education Association, Paris, July 8-13, 2013.
} 
benefits not only for educators but also for learners by implementing DiE as a teaching medium; the former with respect to lesson planning, the curriculum and budgetary concerns; and the latter with respect to interactive, inclusive, engaging, participatory and fun learning.

According to the Greek Constitution, the government is required to offer a mandatory, public, and free nine-year educational system for all children aged six to fifteen years. Private education in all grades is also offered (The Archive of Ministry of Education 2012).

Greek primary school (Dimotiko) consists of six grades (year 1 - year 6), lasts for six years, and caters for children aged six to twelve years. In the majority of all the educational grades, from primary school to high school, English language teaching (ELT) is mandatory. , English was first introduced into the Greek curriculum as a result of its widespread use as the most prevailing language of trade in the beginning of the twentieth century (Evaggelia 2007). Today, a multi-fold reform programme under the title The New School - the School of the Twenty-first Century concerning primary and secondary public education, has been introduced by the Panhellenic Socialist Movement (PASOK) in 2009 (Sotiropoulos 2012: 115). A part of this project includes a pilot programme, ESPA 2007-2013, which was developed under the aegis of the National and Kapodistrian University of Athens and Ministry of Education, Religious Affairs, Culture, and Sports. It involves ELT in the first three years of public primary schools, aiming at cognitive development, cognitive skills, personal and social development, diversity and multilingualism, and setting the base for a further language learning development (RCEL, University of Athens 2012). Accordingly, Greek pupils are exposed to the English language from an early age. However, Greece is one of the European countries that have been significantly affected by the financial turmoil beginning in 2007. According to Lyritzis (2012), Greece is currently struggling with a severe and protracted economic crisis, with strikes against austerity measures, and is facing unstable political conditions. Consequently, several shortages in teaching equipment, such as interactive whiteboards and the latest publications of textbooks, are widespread. Due to insufficient funds there is also limited employment of new, young, and highly qualified staff, especially for ELT in primary schools. In other words, Greece is considerably weakened facing sizeable cuts in all kinds of welfare spending, in education, and in health services (Tzotze 2012: 8).

Thus, it is essential to provide teachers with teaching methodologies that are affordable for schools and, at the same time, will engage and motivate learners. This paper advocates DiE to be such a methodology.

\section{Drama in Education}

The term 'Drama in Education' was first presented in the 1950s as part of the Progressive Education movement in the British educational system (Newsome 1963). More precisely, the positive contribution of theatre and drama and their beneficial impact on the social and intellectual development of children 
continued to grow as it is mentioned in John Newsom's report (1963). According to Röhrs and Lenhart (1995), the cornerstone of Progressive Education was the child's experiential and active learning in school, which should be a vital and vibrant space whereby the child could develop itself, nurture its talents and improve its skills. It is also worth noting that Progressive Education advocated that learners should learn by doing, because 'play' and 'arts' in the school environment significantly contribute to the child's creative and free self-expression, and to the holistic development of its personality. Not only teachers but also learners needed a new educational model that would value play and collaborative learning and would also transform the teacher-centred educational system into a student-centred one (Nicholson 2009: 13).

Generally, the arts in education challenge the notion of the educator as 'the one who knows', obliged to transfer his or her existing knowledge to the learner, 'the one who does not know' (Freire 1985: 114). As Freire states:

In the 'banking' concept of education, knowledge is a gift bestowed by those who consider themselves knowledgeable upon those whom they consider to know nothing. (Freire 1996: 58)

In contrast to this top-down notion, $\mathrm{DiE}$ promotes young learners' imagination, creativity, critical thinking, flexibility and expressivity (Nicholson 2009: 14f), without restricting their own abilities, talents and without limiting their personalities. On the subject of critical thinking, Brecht explained in Lehrstücke, that drama can broaden pupils' horizons, let them explore and share their own ideas, arrive at solutions collectively, and make them think dialectically as productive members of a society (Willett 1964: 79). Thus drama can be the pathway that will lead the participant to knowledge, self-development, and critical thinking. Moreover, through drama, learners are encouraged to express themselves spontaneously and freely (Kalogirou 2012).

According to Maslow:

If we hope for our children that they will become full human beings, and that they will move toward actualizing the potentialities that they have, then, as nearly as I can make out, the only kind of education in existence today that has any faint inkling of such goals is art education. (1971: 55)

DiE as a form of art includes various artistic aspects, and provides learners with another new, fresh and challenging pathway in order to gain the necessary knowledge and experiences. After all, "we learn through experience and experiencing" (Spolin 1999: 3), and this is one of DiE's major characteristics. It offers the opportunity of gaining experiences that are born spontaneously and are based on individual reactions and authentic improvisations. 


\section{Drama: A Teaching Tool for English Language in a Greek Primary School}

The initial question that led to the following case study was to examine if drama can work in the Greek educational system, in which foreign languages are of great importance and the curriculum is, at the same time, very strict and narrow without allowing much space for innovation and experimentation. It is necessary to explain which teaching methodologies are currently being implemented in mainstream primary Greek schools. At the moment, the predominant method is Communicative Language Teaching (CLT) and Content and Language Integrated Learning (CLIL) (Richards \& Rogers 2001). The post-communicative method, where the primary function of language is effective communication, is also used. (Ur 2012). All of these methods focus on communicative tasks in the target language, with explicit teaching of grammar, vocabulary, punctuation, and spelling. Technology is considered a key tool of modern teaching, and for that reason, Computer-Assisted Language Learning (CALL) is also used, with the Interactive Whiteboard (IWB) at its core. However, due to limited funds, the CALL is least developed because there are not enough resources with which to equip all schools. As a result, English in Greece is being taught with traditional methods in modern guise, with the aim to assist learners in achieving a high score in the Common European Framework of Reference for Languages Exams (CEFR) and should acquire, by the end of year 6, the B1 level (independent user).

CLT creates the impression that students learn to use the target language for their own communicative purposes, while authority and control continue to be in the hands of the teacher (Evans 1997). Teachers still appear to favour a top-down style of teaching, while the students' main classroom roles consists of listening to the teacher and working individually on examinationfocused exercises. Moreover, according to Li (2001), low proficiency learners, and some beginners show lack of motivation for developing communicative competence due to the high level of stress they encounter to present high-quality communication skills in front of the rest of the class without having enough time for preparation and practice. This is understandable because CLT, while being a simulation of contexts in which the target language is used, fails to provide a safe learning environment. DiE, however, can be implemented as a supplementary teaching tool to support CLT, and together, a combination of these two approaches can lead to successful, productive, and enjoyable English lessons. More specifically, $\mathrm{DiE}$ is an adaptable tool that can keep up with the curriculum and the syllabus that has to be covered for the sake of the exams. Furthermore, DiE activities can be implemented and designed according to each school's budget and each class's needs which will satisfy the majority of teachers' requirements and learners' expectations, since DiE activities require neither special equipment nor expensive textbooks. DiE activities can be based on the use of everyday objects, props from classrooms, things from teachers' and pupils' households, and even from imaginary objects. After all, imagination and 
creativity are endless and free.

\section{The Case Study: Teaching English through Drama in a Greek Primary School}

At the beginning of the school year, topics from first textbooks, such as "means of transport", "weather forecast", "organizing holidays in Africa", had been taught with the CLT method, following the conventional way of teaching, such as dictations, written examinations, listening to textbooks and CDs, and reading aloud chapter texts. DiE was chosen as the teaching medium for the topic "British culture and heritage", and a pre-evaluation took place, so as to ensure firstly, that pupils were not familiar at all with the topic, regarding information and vocabulary, and secondly, to examine DiE's efficiency as a teaching methodology.

Initially, the teacher began the lesson by asking the pupils to think of a game that would help them to introduce themselves. So they came up with the idea of "catch the ball and say your name". The prop for this game was a scrap-paper ball. It was a unique moment to see on pupils' faces the excitement of playing a game during an English lesson because it was the very first time they had a chance to play a name game in English. The teacher played a few drama games in order to examine dictation. Teacher and pupils played a devised version of a pantomime, in which the leader (a randomly selected person each time) had to describe physically, without speaking at all, one word of his/her choice from the dictation words, and the rest of the class wrote down on a piece of paper what word or person or action the leader was acting. Additionally learners played a devised version of hangman. In preparation for that game, paper collage puppets inspired from the famous personalities of Great Britain, had been made by the class. So while learners in groups of four were trying to figure out the given word and complete the missing letters, they were losing a part of their paper puppets for every unsuccessful attempt. So the winner group was the one which had the most pieces left of the puppets. The pupils enjoyed these participatory games a lot, which also helped to build vocabulary skills, spelling practice, self-expression, and use of imagination. Wrong guesses in pantomime and picking the wrong letters in hangman were not considered mistakes or lack of knowledge. Instead, pupils and teacher used the false attempts to boost the class to go on trying, and encouraged pupils who did not succeed in the first place not to give up or feel embarrassed. Moreover, the use of drama games and improvisation allowed learners to gradually and safely approach the target language with limited stress levels and significantly less anxiety for the outcome. After the target vocabulary had been introduced and experienced through games, it was apparent from their dictation scores that the vocabulary items had been successfully acquired. The next goal was to assist learners to put this target vocabulary into context. This goal would be achieved through DiE and team research, presentation, and discussion.

To do this, the whole class worked collaboratively to create a class magazine. 
The task was designed around a variety of drama activities to demonstrate the British culture, heritage, greatest landmarks, famous people, and old-time customs.

In the first class, the teacher introduced the Wise Magic Hat, and then asked a random 8 of the 16 pupils to choose a card from the hat, without looking at any of the pictures that were inside the hat. Pupils had to respect Wise Magic Hat's decision, keep their card secret and stand in line. Then the rest of the class, namely the other 8 pupils, got together with a partner of their choice and work collaboratively, researching the picture they had in their hands and write a few facts about it. These pictures presented some of the main symbols of British culture, such as Queen Elizabeth II, London, Cricket, Scotland Yard, Winston Churchill, Stonehenge, Pounds, Harry Potter, and many others. This activity was designed in such a way that pupils would learn to deal with events without complaint and negative thinking, such as the possibility of choosing a card that might not be of their main interest. It also encouraged them to be active decision-makers and choose according to their personal criteria the partner with whom they could cooperate the best. So DiE as a teaching medium can provide a truly student-centered lesson as referred to by Nicholson (2009).

In the following classes, the pupils worked in pairs, collected information from relevant books and the internet, shared the information with their partners and created a range of fact cards about their topic. This process of collaborative research and collective work not only enhanced their research, scanning and skimming skills, and cultivated their synthetic thinking, but also enriched their knowledge about British culture. All these classes led smoothly to the part in which learners were asked to play a Taboo game as a class with the fact-cards they had created. In this game, pupils had to describe the person/object of the fact-card they had in their hand without naming it but using the written facts about it. As it turned out, the pupils truly enjoyed playing Taboo, and it was apparent from their responses and reactions that it had boosted their self-confidence and interest because they had invested personal time and energy on this game. This game offered a safe environment for pupils because during the game, pupils did not show any hesitation or worry about their pronunciation or accent because they felt that the most important requirement of the moment was to play, to use the language in order to pass on the message, and have fun. The reason the Taboo game had been chosen was because learners would be able not only to design the game themselves but also to revise, recycle and share the target information about the British culture in a creative and fun way. Last but not least, through this game, pupils improved their interpersonal relationships, learned from each other's mistakes, skills and talents, improved their manners, respected each other's opinion and preferences, and shared school resources and equipment such as: paper, crayons, glue, scissors and all the resources they needed to design the game. Moreover, linguistically speaking, this activity improved pupils' speaking skills and vocabulary because, in avoiding saying the actual names of the depicted pictures, they had to use all the already acquired vocabulary items in addition to the new ones, to communicate the word, and 
win. One girl, while attempting to describe the Scotland Yard officer fact-card, stopped saying the provided information, because the class seemed to be stuck, and narrated a short scene from Sherlock Holmes' stories. To make it more obvious and easier for the rest of the class, she spontaneously asked two of her classmates to help her act out the scene she was narrating, in order to present a more detailed description of the job of a Scotland Yard officer, and win one point. It was remarkable to observe the children's free associations and the way their imagination led them from the symbol of a culture to the creation of a story.

At the end of the second month, and after having been exposed to various warm-ups and Taboo activities, pupils completed their allocated task successfully, and created a sixteen-page magazine that included a variety of British cultural information. In the last lesson, each pupil presented his or her topic in front of the class, and answered questions afterwards. All pupils appeared to be satisfied with the outcome and to feel proud of themselves. Pupils' speaking, reading, listening, and writing skills had been significantly improved, according to the post-evaluation that followed.

\section{Method}

\subsection{Material}

All props and artefacts such as a velvet hat, a ball from scrap paper, pencils, felt pens, card paper, crayons, sello-tape, glue, stapler, laminating pouches, printed photos, books from the school's library, course books, dictionaries and the school's computer for information research were materials used in their classrooms. They were of little or no cost and required minimum preparation on behalf of the teacher. Taking into consideration the struggling economic situation of Greek primary schools at the time, it has to be emphasised, that it was a distinct advantage that DiE as a teaching methodology did not require expensive equipment or high cost resources.

\subsection{Participants}

The case study took place in a Year 4 class in a Greek primary school where English is taught as a foreign language. The pupils were sixteen mixed-gender, native Greek pupils, aged nine to ten years. The majority of the class was B1 level according to CEFR with a few lower-level pupils. The case study lasted two months, took place two days per week, with the duration of each lesson being fifty minutes. In total, the project was completed in 16 teaching hours. The teacher was native Greek, in her mid-twenties, with a master's degree in Applied Drama in Education. She taught and examined exclusively in English. She had to follow an already-existing curriculum and course books which contained standard topics that would be assessed by the end of the school year.

Participation in the study was voluntary, and informed consent was gained from all participants. All pupils attended every lesson and took all pre-study 
and post-study tests. Evaluation results were also taken into consideration for pupils' final grades in the English lesson. The post-study test scores were used as the chapter's test scores, and also helped pupils to achieve a good mark in their final exams because of the innovative and creative practice they had experienced.

The majority of the pupils achieved the following marks: 17,18 and 19 out of 20 and proved good knowledge of the overall taught syllabus. The evaluation process was conducted in two parts in order to observe any progress regarding pupils' knowledge and competence about the target topic i.e. the British culture and heritage.

In the first part, a pre-evaluation test was administered to all pupils to assess prior knowledge of the target vocabulary and a post-evaluation test was given immediately after the final lesson. The aim of the pre-evaluation was to determine the class level in reading, writing, speaking, and listening, and particularly their vocabulary knowledge about the target topic.

\subsection{Evaluation Form}

The evaluation form consisted of three written activities. The first activity required pupils to answer, nine general-knowledge questions about the United Kingdom in complete sentences, such as "Who is the queen of the UK?" "Who is the author of Harry Potter?" "What is the currency in the UK?" etc. The second was a multiple choice vocabulary activity where learners had to choose the most appropriate adjective among four options, such as, "London has been always an important / impolite / impossible / impatient trade centre", "A ride on one of the world's tallest observation wheels offers an exciting / practical / exotic / breath-taking experience", etc. The third activity required pupils in pairs to play Taboo. In other words, they were given a picture and had to describe it to their partner, saying the facts they already knew about it without naming it. They were allowed to use physical actions and/or improvisations to enrich their descriptions.

The evaluation form, consisting of these three activities, aimed at examining learners in the same way they had been taught. Therefore, the first activity was based on general knowledge derived from research accomplished through reading books or websites, and also examined the writing skills of the pupils (structure of a sentence, punctuation, vocabulary etc). The second one was vocabulary-oriented because adjectives are key vocabulary tools that are required to describe people and places. The multiple choice activity examined whether pupils could make their own decisions. The third one was designed to examine pupils' communication skills, imagination and creativity which were all necessary to create an informative magazine in order to provide evidence that the pupils were informed on the topic they were writing about, that they were able to express themselves in the target language, and to what extent they could use it appropriately. Moreover, the task of collaboratively creating a class magazine highlighted a range of capacities and skills that a learner has to 
develop, such as collaboration, cooperation, exchanging ideas, creativity and imagination.

\section{Results}

As it has already been explained above, in order to have results that were as accurate as possible, the same format was implemented both for pre-test and post-test evaluation. As expected, in pre-test all 16 pupils scored very low in each activity. This can be easily explained since practically none of the pupils knew the topic or knew about British culture and persona in general. Moreover, most of the pupils found the second question difficult as well, because they were familiar neither with the target vocabulary nor with the multiple choice assessment. Finally, in this particular Greek primary school, drama games and activities had never been implemented before as a teaching medium, so pupils found it strange to play taboo in an English lesson and give information about Queen Elizabeth II or pretend to be Sherlock Holmes.

In post- test all of the participants achieved very high scores and answered all of the questions, most of them accurately. They were able to write in full sentences all the necessary information about the person or the object they had been asked, since they had practiced their writing skills during these 16 lessons. They were also able to choose independently the right adjective to fill the gap in the given sentences because they had read and researched a lot about the target topic. Finally, they were familiar with playing Taboo after 16 lessons and were acquainted with the drama tools such as improvisation, imitation and acting. Consequently, based on these pilot research results, DiE appears to be a successful teaching tool for English Language in young learners. All of the pupils showed great improvement in post-tests regarding their general knowledge about British culture and heritage, in their reading, writing, listening and speaking skills, and in their cooperation, collaboration, active participation and self-motivation skills.

\section{Satisfied Pupils}

The pupils and I, as project teacher, agreed that DiE was worth our time and our attention as a teaching medium. In fact, learners expressed their interest in participating in similar projects and asked if drama activities could be integrated into the teaching of the rest of the textbook's topics. Even though the head teacher had been reluctant at the beginning of the project, she became convinced of DiE's value as a creative, motivating, and affordable tool that could be applied successfully, even in an English class whose main goal, apart from language learning, is high scores in the final tests.

As an English teacher, I support the notion that teaching should be studentcentered and designed according to the needs of each class. In this project, the entire general frame for the activities was designed by the teacher, whereas the 
actual process, duration and decision making was determined by the pupils. The pupils had the opportunity to suggest their own activities, such as the ice breaker 'catch the ball and say your name' or lead the warming up activities such as the pantomime and the hangman. Moreover, pupils demonstrated active participation in the decision-making which was required in the Taboo game. They had to choose their partners, decide what resources they would use to make their fact cards and what sources of information they would use to do their research. Furthermore, pupils took part in discussions, designed the structure of their own class project - the class magazine about British culture and heritage entitled 'OUR MAG' - and explored its topics by working collaboratively and creatively in groups. Additionally, the classroom desks were arranged in circles so that the small groups could communicate and cooperate better, rather than having rows of desks that faced the teacher.

Additionally, I reckon that learning should not only be about improving the four language skills, writing, reading, listening and speaking, but it should also be joyful, spontaneous, participatory, inclusive, interactive, and having the communication in the target language as its main goal. Thus, this paper presents DiE's beneficial contribution to the teaching of English as a foreign language, even within a strict, grade-oriented curriculum as the one in Greek primary schools. This paper also presents a case study that is interesting, appealing, and practical for every language teacher who struggles with tight curricula, and who looks for new ideas that would allow him or her to motivate and encourage young learners to actively participate in the lesson. The initial idea behind the implementation of DiE as a teaching medium is to promote collective work, student-centered learning and joyful use of the English language. Teacher and learners welcome a more creative, safe, fun and productive learning process and, according to the described project above, this change can be achieved successfully with DiE as a teaching medium. Language lessons in particular, whose aim it is to teach how to communicate in a foreign language, should encourage learners to discuss, ask, make decisions, and have a critical point of view on everything they read or listen to. In this project, we tried to cultivate this way of thinking in our pupils by having them to explore the English language through projects of their own preference, drama activities and physical interactions in order to become more confident in using the target language and to enjoy the learning process.

In sum, after regular evaluation of the pupils' learning progress throughout the school year and receiving their spontaneous feedback, I can happily confirm that this particular project, in which learners had the opportunity to lead activities, introduce their own ideas, learn the target information, key vocabulary, and the application of a grammar rule through DiE, revealed the best scores in evaluations by far, and most importantly, the most exciting comments from learners. My teaching team and I came to the conclusion that CLT and DiE can coexist and that, in fact, their combination offers educators the chance to have a more interesting, appealing, and interactive lesson that promotes collective work and learners' engagement. Last, but not least, the use of DiE as a teaching 
methodology was very affordable, and did not cost anything extra to the school's budget since the materials which had been used were the already-existing class resources and learners' creativity. Consequently, this case study demonstrates that DiE can be implemented by English teachers as a learning medium at no extra cost, provide learners with interactive and stimulating lessons, and be the trigger for learners' engagement and active education even in the most challenging, demanding and poorly funded education systems, such as the one that currently exists in Greece.

\section{Bibliography}

Baldwin, Patrice \& Hendy, Lesley (1994): The Drama Book: An Active Approach to Learning. London: Collins Educational

Barbu, Lucia (2007): Using Drama techniques for teaching English. http://forum. famouswhy.com/index.php?showtopic=1150 [last accessed June 16, 2015]

Bolton, Gavin (1979): Towards a theory of Drama in Education. London: Longman

Bowell, Pamela \& Heap, Brian S. (2013): Planning Process Drama, Enriching Teaching and Learning. Oxon: Routledge

Bräuer, Gerd (ed.) (2002): Body and Language: Intercultural Learning Through Drama. Westport, CT: Ablex Publishing Corporation

Brecht, Bertolt (2010): The Measures Taken, and other Lehrstücke. Berlin: Methuen Publishing

Brennan, Ross (2008): Educational drama: A tool for promoting marketing learning? In: International Journal of Management Education 8/1, 1-9

Dewey, John (1921): The School and Society. Chicago: University of Chicago Press.

Evans, Stephen (1997): Teacher and learner roles in the Hong Kong English language classroom. In: Educational Journal 25/2, 43-62

Freire, Paul (1996): Pedagogy of the Oppressed. London: Penguin

Hayes, Susan K. (1984): Drama as a Second Language. Cambridge: National Extension College Trust

Heathcote, Dorothy \& Bolton, Gavin (1995): Drama for Learning: Dorothy Heathcote's Mantle of the Expert Approach to Education. Portsmouth, NH: Heinemann

Hornby, Albert Sidney (1950): The situational approach in language teaching. A series of three articles in English Language Teaching 4/5, 98-104, 121-128, 150-156

Howatt, Anthony (1984): A history of English language teaching. Oxford: Oxford University Press 
International Monetary Fund (IMF), (2011): Greece: Letter of Intent, Memorandum of Economic and Financial Policies, and Technical Memorandum of Understanding. November 30, 2011.

http://www.imf.org/external/np/loi/2011/grc/113011.pdf [last accessed June 16, 2015]

Kalogirou, Konstantina (2012): Drama: a vehicle towards creative, interactive and joyful English Language Teaching. M.A. thesis. Goldsmiths College, University of London

Kao, Shin-Mei \& O'Neill, Cecily (1998): Words into Worlds. Learning a Second Language Through Process Drama. Westport, CT: Ablex Publishing Corporation

Kim, Le, Su (1995): Creative Games for the Language Class. In: Forum 33/1, 35

Lyrintzis, Christos (2011): Greek Politics in the Era of Economic Crisis: reassessing Causes and Effects. In: Hellenic Observatory Papers on Greece and Southeast Europe 45, 1-24

Maley, Alan \& Duff, Alan (1979): Drama Techniques in Language Learning. Cambridge: Cambridge University Press

McDonough, Jo; Shaw Christofer \& Masuhara, Hiroshi (2013): Materials and Methods in ELT (3rd ed.). Chichester, West Sussex: Wiley-Blackwell

Neelands, Jonathan (1990): Structuring Drama Work. Cambridge: Cambridge University Press

Neelands, Jonathan (1984): Making Sense of Drama, London: Heinemann.

Newsome, John (1963): Half our Future. London: Ministry of Education, Her Majesty's Stationery Office

Nguyen, Thi Thanh Huyen and Khuat, Thi Thu Nga (2003): Learning Vocabulary Through Games. In: Asian EFL Journal 5/4.

http://www.asian-efl-journal.com/dec_03_vn.pdf [last accessed June 16, 2015]

Nicholson, Helen (2009): Theatre and Education. Basingstoke: Palgrave Macmillan

O’Neill, Cecily (1995): Drama Worlds: A Framework for Process Drama. Portsmouth, NH: Heinemann

Rohrs, Hermann. \& Lenhart, Volker (1995): Progressive Education Across the Continents: A Handbook. Berlin: Peter Lang Pub Inc

Richards, Jack \& Rodgers, Theodore (2001): Approaches and Methods in Language Teaching. Cambridge: Cambridge University Press

Sotiropoulos, Dimitris, (2001): The politics of education reform in Greece. In: SEESOX (South East European Studies at Oxford), Conference: Whose Crisis: Greece's Politics, Economics and Society in an Era of Uncertainty. Oxford, United Kingdom May, 2011. Oxford: SEESOX.

http://www-old.sant.ox.ac.uk/seesox/pdf/SotiropoulosPaper.pdf [last accessed November 9, 2015] 
Soulioti, Evaggelia (2007): Teaching English Language in the Greece during from 1913 to 1967: Case study of Municipality of Ioannina; Methodological, didactic, historical extensions and Comparisons with modern approaches. $\mathrm{Ph}$. D. University of Ioannina

Spolin, Violin (1999): Improvisation for the Theater: A Handbook of Teaching and Directing Techniques. Illinois: Northwest University Press

Tanaka, Takako (2009): Communicative Language Teaching, and its cultural appropriateness in Japan. In: The Literary Association (Doshisha University) $84,107-123$

Tzotse-Lanara, Zoe (2012): The Impact of Anti Crisis Measures and the Social and Employment Situation, Greece.

http://www.eesc.europa.eu/resources/docs/qe-31-12-350-en-c.pdf [last accessed October 8, 2015]

Ur, Penny (2012): A course in ELT (2nd ed). Cambridge: Cambridge University Press

Winston, Joe \& Tandy, Miles (1998): Beginning Drama 4-11. London: David Fulton Publishers Ltd

Wright, Andrew; Betteridge, David \& Buckby, Michael (1984): Games for Language Learning (2nd ed). Cambridge: Cambridge University Press

Wright, Andrew (2005): Games for Language Learning. New York: Cambridge University Press 


\section{Appendix}

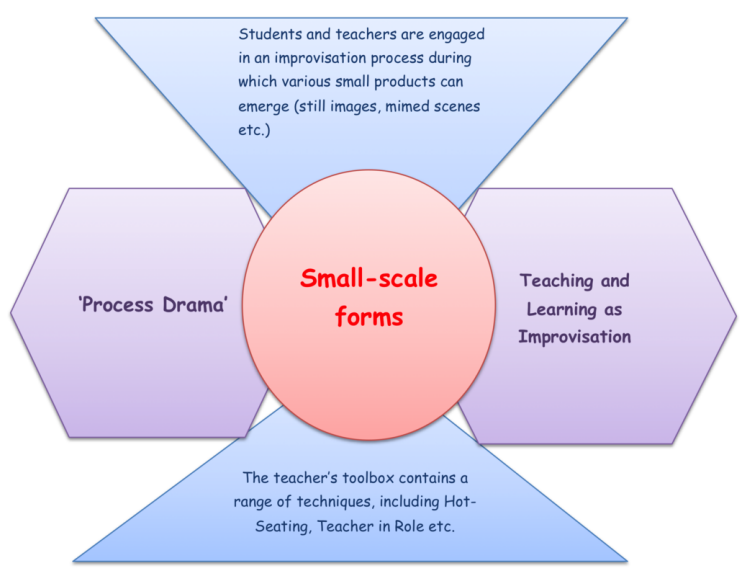

Fig. 1: The Class Magazine Our Mag.

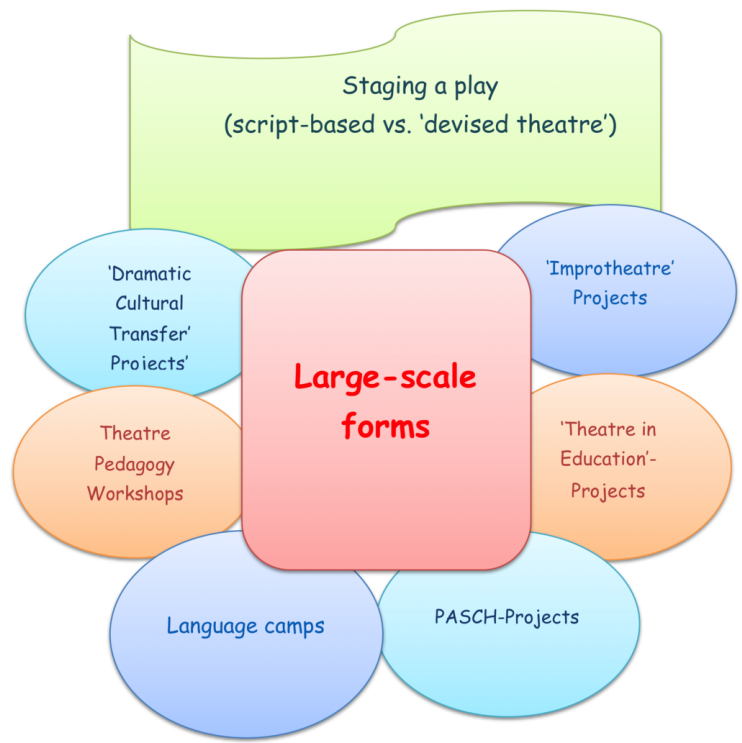

Fig. 2: Her Majesty The Queen Elizabeth II.

Fig. 3: Cricket

Fig. 4: Letter with feedback from the participants. 


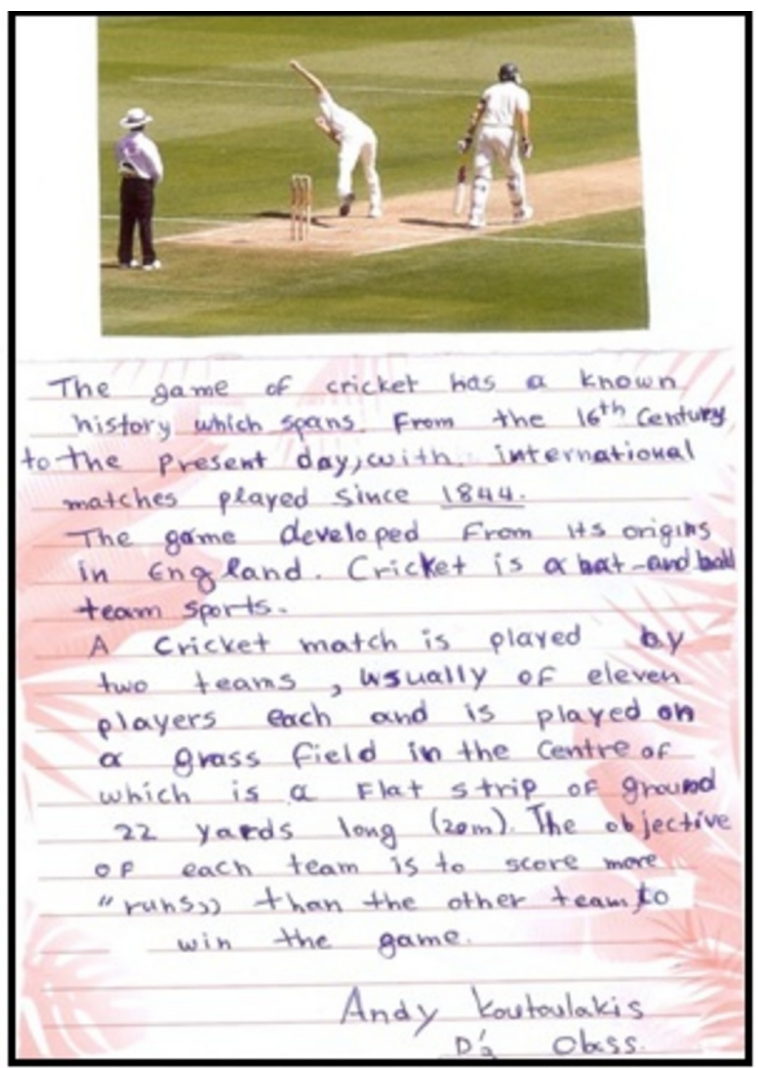




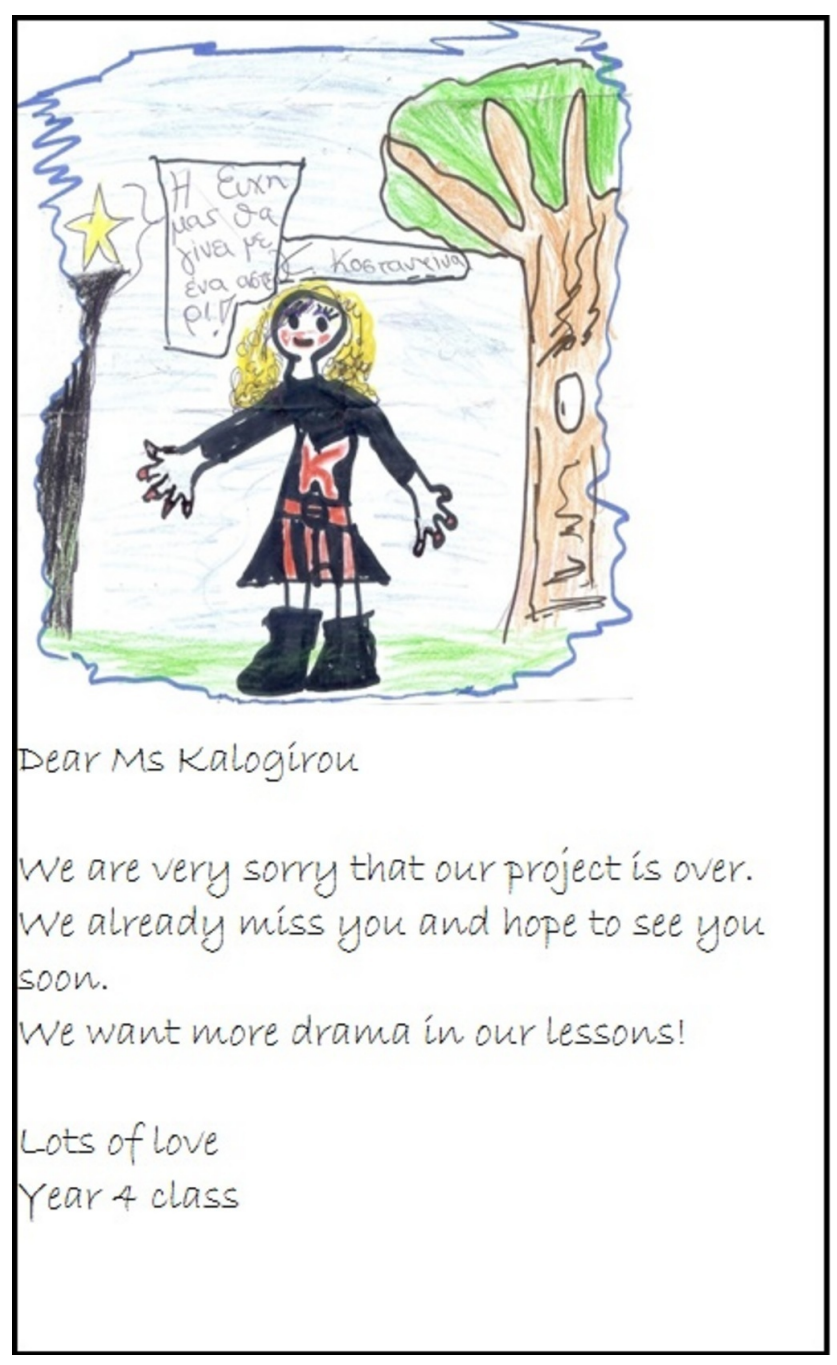

